NOTICE: this is the author's version of a work that was accepted for publication in Microchemical Journal. Changes resulting from the publishing process, such as peer review, editing, corrections, structural formatting, and other quality control mechanisms may not be reflected in this document. Changes may have been made to this work since it was submitted for publication. A definitive version was subsequently published in Microchemical Journal, Vol. 111 (2013). DOI: 10.1016/j.microc.2012.08.005 


\section{Infrared Microscopy Studies of the Chemical Composition of Latent Fingermark Residues}

$\underline{\text { Patrick FRITZ }}{ }^{1}$, Wilhelm van BRONSWJIK ${ }^{1}$, Katerina LEPKOVA ${ }^{1}$, Simon W. LEWIS $^{1}$ *, Kieran F. LIM (林百君) ${ }^{2}$, Danielle E. MARTIN ${ }^{3}$ and Ljiljana PUSKAR ${ }^{3}$

${ }^{1}$ Nanochemistry Research Institute, Department of Chemistry, Curtin University of Technology, GPO Box U1987, Perth, Western Australia 6845, Australia;

${ }^{2}$ Department of Chemistry, University of Canterbury, Private Bag 4800, Christchurch 8140, New Zealand; Permanent address: School of Life and Environmental Sciences, Deakin University, 221 Burwood Hwy, Burwood, Victoria 3125, Australian;

${ }^{3}$ Australian Synchrotron, 800 Blackburn Road, Clayton, Victoria 3168, Australia.

*Author for correspondence:

Simon W. Lewis

Department of Chemistry, Curtin University

GPO Box U1987 Perth, Western Australia 6845

E-mail: S.Lewis@ curtin.edu.au Tel: +61 (08) 92662484

Submitted to Microchemical Journal, 28 June 2012

Revision submitted 9 August 2012 


\begin{abstract}
Synchrotron-infrared microscopy provides a non-destructive technique to investigate the chemical composition of latent fingermarks in-situ. The high spatial resolution and brightness of the synchrotron source also lends itself to the chemical characterisation of trace amounts of material on surfaces. However, only the lipid fraction of fingermark deposits is targeted when transmission-reflection is used. The fingermark lipid residues appeared to be relatively homogenous in composition across the deposit for any particular donor. No significant variation in the lipid composition as a function of age or gender of the donor was observed.
\end{abstract}

Investigations into fingermark degradation were carried out by collecting spectra from fingermarks at three month intervals. An overall decrease in signal intensity was observed, ascribed to evaporation of the fingermark deposit. Greatest loss of material appeared to occur during the first 3 months following deposition. However, no significant variation in lipid composition was detected over a 9-month period.

The outcomes of this study indicate that latent fingermark visualisation reagents that target lipids should produce accurate and reliable renditions of fingermarks irrespective of the age or gender of the donor, albeit with reduced sensitivity as the fingermark ages.

\title{
Keywords
}

Latent fingermarks; infrared microscopy; synchrotron 


\subsection{Introduction}

A range of chemical reagents can be used to treat and consequently visualise latent fingermarks. These react with the deposited fingermark residue consisting of both foreign compounds and sweat secretions from skin glands. These secretions are the result of the eccrine, apocrine and sebaceous glands, of which only the eccrine gland is present on the palms and fingers [1]. The sebaceous and apocrine glands are in skin found throughout the body and their secretions can be transferred onto the hands by touching other body parts [2]. As shown in Table 1, an array of organic and inorganic constituents has been discovered to be secreted by these glands [1, 3-7]. However, the exact chemical composition of fingermark deposits is still widely unknown as research studies in the past have focused on bulk production of sweat, not necessarily the unique mixture that is present in fingermark deposits $[1,8,9]$. It has been noted that the quality of fingermarks treated with reagents such as 1,2indanedione are not consistent within a donor population, with age, gender, prior activity and diet thought to be possible causes [3, 10-13]. Furthermore, the density of sweat pores, the pores' size and shape, as well as the physical contact that occurs when placing fingermarks (such as pressure and contact time) $[14,15]$. While there are a growing number of recent studies that investigate fingermark secretions, these mostly focus on chromatographic and mass spectral techniques [16-20]. In addition, the age of a deposit can have a significant effect on the ability to detect it, with some reagents reacting better with fresh fingermarks, while other develop increasingly well with an ageing print [4]. However, the effect of ageing on fingermarks has not been extensively researched $[3,4,12,13,16-20]$. As the chemical reaction that occurs between a reagent and the fingermark deposit is directly dependent on its chemical nature, a deeper understanding of its chemistry and ageing process are vital for the progression of development techniques.

Infrared (IR) spectroscopy has successfully been applied previously to analyse latent fingermark deposits, and can provide complimentary information to recent chromatographic and mass spectral research [2, 5, 6, 16-21]. However, conventional, glow bar sourced IR spectrometers may not display adequate sensitivity and spatial resolution required for these analyses. Preliminary research has been conducted by Perry et al. and Wilkinson et al. [22, 23], indicating that synchrotron sourced IR microscopy (IRM) is a viable and improved technique over conventional IR microscopy that could be very lucrative for the analysis of latent fingermarks. The high spectral brightness and collimation of a synchrotron IR beam 
greatly improves the signal-to-noise ratio of collected data, and when in combination with microscopy is able to achieve much higher, diffraction-limited spatial resolutions at higher sensitivity than possible with a conventional IR source [22-24]. IRM therefore provides an excellent research tool for the study of thin layer and complex samples and is thus uniquely suited for the chemical micro-analysis of latent fingermark compositions in-situ.

The aims of this study are to demonstrate that synchrotron sourced IR is superior to conventional IR for in-situ fingermark studies. Furthermore, we will attempt to ascertain if a relationship exists between the age of the prints and their chemical composition.

Additionally, we will attempt to establish a connection between the fingermark secretions as a function of the gender and or age of the donor. The importance of substrate choice in terms of interference, stability and mode (reflection or transmission) of analysis will be investigated.

\subsection{Material and methods}

\subsection{Collection of latent fingermarks}

Donors were asked to wash their hands 30 minutes prior to sample deposition and were not permitted to consume food or handle chemicals before providing the sample. Donors were asked to rub their fingers onto their face or hair for charged fingermarks immediately prior to collection. For uncharged fingermarks donors were asked to refrain from touching their face or hair after washing their hands.

\subsection{Sample preparation}

Samples were tested in both transmission mode, where the IR beam is passed through the sample deposited onto an IR transmissive substrate, and trans-reflection (transflection) mode, where the sample is deposited onto a reflective surface such that the beam is effectively passed through the sample twice as it reflects off the substrate surface. Transmission is said to yield superior quantitative and reflection superior qualitative results [25, 26]. However, the sensitivity achieved utilising reflection mode is several orders of magnitude lower than analyses by transmission mode due to scattering effects as the beam is reflected at various angles from the surface of the deposits (Mie scattering) [25, 26]. This phenomenon can also give rise to a curved baseline depending on the amount of scattering and the angle of the IR beam as it enters the IR detector [25-27]. A number of substrates for sample deposition were 
tested during this study, including; potassium bromide (KBr) (J.T. Baker, United Kingdom) discs, gold-coated glass plates, polished stainless steel plates, zinc selenide (ZnSe) discs (Specac, USA) and germanium substrates (Specac ATR crystal, USA).

$\mathrm{KBr}$ discs were prepared in-house using a Pellet Press (Specac, USA); a maximum of 8 tonnes of load was placed on $\sim 300 \mathrm{mg}$ of $\mathrm{KBr}$ for 1 minute to produce each disc.

Fingermarks were then deposited on these discs and analysed after 1, 10, 20, 30, 50, 100 and 200 fingermarks from a single donor were superimposed. There was no discrimination as to which side of the disc the fingermark was deposited on. The fingermarks were charged after every 10 depositions.

For the deposition of fingermarks on the gold-coated glass and polished stainless steel plates all substrates were first washed using either soft tissue or cotton wool and detergent, followed by rinsing with ethanol and distilled water. The fingermarks were subsequently deposited by pressing the required fingertip onto the substrate.

All fingermark samples for aged analysis were stored in ambient conditions. However due to the hygroscopic nature of $\mathrm{KBr}$, these discs were wrapped in aluminium foil and stored in an oven at $100^{\circ} \mathrm{C}$.

\subsection{Infrared microscopy}

For the preliminary study of fingermarks on KBr discs, a Perkin Elmer ${ }^{\circledR}$ Spectrum $^{\mathrm{TM}} 100$ FTIR spectrometer, using Perkin Elmer software, Spectrum ${ }^{\circledR}$ (v. 6.3.2) was employed in transmission mode. For all subsequent analyses, two different IR microscopes were used as part of this study. Spectra were collected using either a Bruker A590 microscope coupled to a conventional-sourced Bruker IFS V66 spectrometer and using Bruker software OPUS v2.2; or a Bruker Hyperion 2000 microscope coupled to a synchrotron-sourced Vertex V80v spectrometer and using OPUS v6.5. Both IR microscopy spectrometers used liquid nitrogen cooled mercury cadmium telluride (MCT) detectors. All spectra were analysed using OPUS v6.5 software. Unless otherwise stated, the instrument parameters used for fingermark analyses are as presented in Table 2. 


\subsection{Results and discussion}

\subsection{Preliminary considerations}

\subsubsection{Choice of substrates}

In recent studies, various substrates have been used for the collection and the deposition media for latent fingermarks [2, 4-6, 21]. Two main factors have to be considered: firstly, that the substrate can be used with the analytical tool of choice; and secondly, that it permits the long-term study of the fingermarks. A number of substrates were tested to assess their suitability with IR microscopy, in both transmission and reflection measurement modes, and also that allowed the in-situ analysis of latent fingermarks over extended periods of time and under realistic ageing conditions. Suitable substrates that were stable, non-reactive and relatively cheap included gold-coated glass and polished stainless steel plates for reflection studies. Their relatively large surface area enabled up to eight fingermark samples to be deposited on each plate. ZnSe and germanium substrates suitable for transmission analysis were also explored and offered improved sensitivity; however the available $\mathrm{ZnSe}$ and germanium substrates were too small for more than one fingermark and were much more difficult to handle and store. Therefore, taking into consideration the scale, timeframe and availability of resources for this study, glass and metal plates were utilised.

\subsubsection{Peak assignments}

There has been some indication in recent literature as to the bands that can be expected from the IR analysis of latent fingermarks. These are listed in Table 3 [2]. Although not all expected signals were present in each spectrum, all bands were encountered in the course of this study.

\subsubsection{Conventional glow bar source infrared microscopy}

\subsubsection{Fresh fingermarks}

A preliminary study into the use of IR microscopy for latent fingermark analyses used $\mathrm{KBr}$ substrates to give an indication of the spectra expected from synchrotron IR studies. As the deposition of one fingermark on the disc resulted in very low absorbances, more fingermarks were placed on in increments and it was found that the quality of the spectra did not improve 
after 20 depositions. Due to the hygroscopic nature of $\mathrm{KBr}$, water is attracted to the substrate and this was observed in the resulting spectra. Fig. 1 shows absorbances at $3450 \mathrm{~cm}^{-1}(\mathrm{O}-\mathrm{H}$ stretch), $3280 \mathrm{~cm}^{-1}$ ( $2^{\circ}$ amide N-H stretch), $2923 \mathrm{~cm}^{-1}$ ( $1^{\circ} \mathrm{C}-\mathrm{H}$ stretch), $2854 \mathrm{~cm}^{-1}\left(2^{\circ} \mathrm{C}-\mathrm{H}\right.$ stretch), $1740 \mathrm{~cm}^{-1}$ ( ${ }^{\circ}$ amide $\mathrm{C}=\mathrm{O}$ stretch), $1629 \mathrm{~cm}^{-1}$ (O-H bend), $1384 \mathrm{~cm}^{-1}\left(\mathrm{CH}_{3}\right.$ symmetric bend), $1119 \mathrm{~cm}^{-1}$ (C-C-O saturated ester stretch) and at $1040 \mathrm{~cm}^{-1}(\mathrm{O}-\mathrm{C}-\mathrm{C}$ saturated ester stretch). The primary and secondary $\mathrm{C}-\mathrm{H}$ stretch as well as the $\mathrm{CH}_{3}$ symmetric bend are likely due to the glandular secretions, whereas the secondary amide and ester stretches are likely due to skin cell debris.

\subsubsection{Aged fingermarks}

After these initial analyses, the samples were wrapped in aluminium foil and placed in an oven for storage, enabling the effect of strong heat on fingermark stability to be studied. Repeated analysis of these samples over a period of six weeks indicated that the O-H stretch $\left(3450 \mathrm{~cm}^{-1}\right)$ and $\mathrm{O}-\mathrm{H}$ bend $\left(1629 \mathrm{~cm}^{-1}\right)$ absorbances decreased dramatically, while the C-C-O stretch $\left(1119 \mathrm{~cm}^{-1}\right)$ and the O-C-C stretches $\left(1040 \mathrm{~cm}^{-1}\right)$ of saturated esters and the $\mathrm{CH}_{3}$ symmetric bend $\left(1384 \mathrm{~cm}^{-1}\right)$ absorbances remained relatively constant. The $\mathrm{C}-\mathrm{H}$ (lipid) stretches $\left(2923 \mathrm{~cm}^{-1}\right.$ and $\left.2854 \mathrm{~cm}^{-1}\right)$ also decreased in intensity (Fig. 2).

Previous research indicates that the three main reasons for changes in fingermark chemistry are the oxidation of constituents, bacterial action and the evaporation of volatiles [9]. In this experiment, evaporation of volatiles due to heat primarily resulted in a loss of the water and also some decrease in the lipid peak intensity.

However, as the whole fingermark is in the IR beam, targeting points of interest within each fingerprint was not possible. It was therefore likely that the spectra may be the result of a mixture of skin cell debris and glandular secretions, rather than just the glandular secretions of interest [2]. In addition, conventional-sourced IR spectrometers appear to lack sufficient sensitivity for the analysis of single fingermarks, as evidenced by the need to layer multiple prints on the $\mathrm{KBr}$ substrate to gain sufficient signal-to-noise. This limits the use of this technique as a tool for studying in-situ fingermarks. The hygroscopic nature of $\mathrm{KBr}$ discs also makes the long-term storage and analyses of fingermarks very difficult.

\subsubsection{Synchrotron source infrared microscopy}


Initial analysis of latent fingermark deposits at the Australian Synchrotron IRM beamline using gold-coated glass plates indicated that high sensitivity and spatial resolution at low levels of noise could be attained. An ability to operate at diffraction-limited spatial resolutions of between 3 and 5 microns allowed individual glandular secretions as opposed to skin cell debris to be selected for analysis as demonstrated in Fig. 3. Fig. 4 shows a direct comparison of the spectra obtained for fingermarks on polished stainless steel using synchrotron IR microscopy against fingermarks measured using conventional IR microscopy, and clearly demonstrates the significant advantages of the synchrotron IRM in the analysis of latent fingermarks. Fig. 5 shows a comparison of synchrotron IR spectra from latent fingermark deposits obtained using reflection (polished stainless steel plate) and transmission on a $\mathrm{ZnSe}$ substrate. As stated earlier taking into consideration the scale, timeframe and availability of resources for this study, glass and metal plates and reflectance was used for the remaining studies.

\subsection{Skin debris vs. glandular deposits}

The focus of this study is the glandular secretions, as fingermark reagents target and bind to these rather than the skin cell debris, so chemical information about these is more informative to developing new reagents. As Williams et al. [2] displayed in their recent article on the use of IR microscopy for fingermark analysis, there are large chemical differences between the glandular secretions of interest in the study of latent fingermarks compared to skin cell debris. IR absorbances due to debris have been found to be much stronger than those due to glandular secretions. Additionally, uncertainty in how skin cells change chemically over time and as their composition is vastly different to glandular secretions, the ageing patterns are thought to be greatly different to glandular fingermark deposits. As such, the high spatial selectivity of the synchrotron source allowed the acquisition of data more representative of the chemistry of latent fingermarks by the selective measurement of glandular secretions over obvious skin debris. The spectra obtained from different ridges of the same fingermark appeared to be quite homogenous, with the primary difference being the spectral intensity due to varying size and thickness of the analysed secretion. As expected, the chemical difference between fingermark deposits from uncharged and charged prints is much smaller than the variation that exists between glandular secretions and skin cell debris. Eberhardt [28] proposed that cell debris may be the residue of cell walls in oil-secreting glands. Furthermore, as proposed by McIntosh et al. [29], spectra obtained from skin cells 
consists of a much larger percentage of nitrogen in the form of secondary amide $(\mathrm{N}-\mathrm{H})$ stretches present mainly at $3280 \mathrm{~cm}^{-1}$, but also at $1540 \mathrm{~cm}^{-1}$ and $1230 \mathrm{~cm}^{-1}$, due to the proteins present in cells (Fig. 6).

\subsection{Ageing studies}

\subsubsection{Time frame}

Ageing studies were conducted to infer the chemical changes that may occur to fingermark samples over prolonged periods of time. To this effect, fingermark samples from a range of donors (Table 4) were analysed over a nine month period and stored at ambient conditions. The time interval between analyses was determined by the availability of the Australian Synchrotron and a timeframe that offered suitable reference points for the study. Preliminary investigations suggest that the unstable or volatile components will evaporate relatively quickly, whereas the more stable constituents can remain for a very long time, allowing successful fingerprint identification even after 20 years [1].

\subsubsection{Visual sample comparisons}

Spectral comparison of fresh and six-month old fingermarks showed that there was a decrease in the quantity of material making up the fingermark ridges over this period (Fig. 7). Visual comparison of the fingermarks at 36-fold magnification showed that pools of glandular secretions decreased in size, or disappeared altogether, and became lighter in texture over this time period. The reason for this decrease is believed to be due to the evaporation of volatiles, as the oxidation of constituents or bacterial action are unlikely to result in the observed loss of material, unless they were to convert some of the more stable components into volatiles. Inspection of the infrared spectra also indicates no observable chemical change, rather a decrease in the amount of the targeted secretions.

\subsubsection{Changes in chemical composition}

\subsubsection{Identifying chemical trends}

All spectra obtained from fingermark samples included a double band in the $2970-2833 \mathrm{~cm}^{-}$

${ }^{1}$ region, indicative of $\mathrm{C}-\mathrm{H}$ absorbances in fatty acids, and a sharp band in the $1770-1720$ $\mathrm{cm}^{-1}$ region, due to the $\mathrm{C}=\mathrm{O}$ stretch of saturated ester bonds. Integration of the $\mathrm{C}-\mathrm{H}$ stretching vibrational bands provides information concerning the degree of saturation in the sample lipids, which may allow a trend to be identified with either chemical degradation or sample age. Due to the very large uncertainty, the subsequent comparison of the graphs indicated that 
it is not possible to interpret any change that may be occurring between the primary and secondary C-H signals over time. Therefore no particular trend could be established for any chemical change that may occur in the ageing studies of latent fingermarks, except that a general decrease in the amount of the deposit over time was noted (Supplementary Material Fig. S1). The random nature of the comparison of the integration ratio of the lipid to ester stretch, displays that the ratio is very likely only indicative of the loss of oils in the fingermark rather than being attributed to any chemical change or degradation (Supplementary Material Fig. S2). Range normalisation for integration values was not performed as the absolute intensities were utilised to indicate whether a decrease in the absorbances occurred with time.

\subsubsection{Chemometric analysis}

In another effort to identify any underlying trends between the different samples, chemometric analyses was performed on the $3000-2750 \mathrm{~cm}^{-1}$ region of the spectra, as no significant variance was observed outside the aliphatic $\mathrm{C}-\mathrm{H}$ range. All spectra were baseline corrected and range normalised. All pre-processing and statistical analysis of the data was performed using the Unscrambler® X software (CAMO Software AS, Oslo, Norway). Principal component analysis (PCA) was used as an unsupervised chemometric technique to identify any trends in the data according to age and gender of the donors, and to the age of the deposits. However, no particular trends could be observed, as can be seen in the randomness of the plots in Fig. 8. Replicate samples were observed to be as widely distributed on the scores plots as the whole sample set, indicating that inter and intra sample variability is similar. There is thus no discernible IR difference in the lipid composition as function of age or gender. Similarly, no trend is identifiable in relation to the age of the deposits, indicating that selective degradation of the long chain fatty acid esters is not occurring.

In addition to the baseline correction and range normalisation, the spectra were processed using the second derivative data, as this may have revealed smaller changes or hidden bands more easily. This also did not provide any clustering or trends.

Reinforced by the chemometric analyses performed, no trend could be attained. Although the samples were shown to be relatively homogenous chemically within the same deposit and 
between deposits, it is not possible to assess the thickness of the sample. As the path length of the sample is unknown individual intensities cannot be used to assess possible differences between samples and only the relative intensities of bands within a spectrum are of use. The lack of clustering in the PCA scores plots of the $\mathrm{CH}$ stretching region showed significant relative intensity changes did not occur with the spectra we obtained.

The advantages of using synchrotron sourced IR microscopy to conventional sourced IR microscopy were established in its ability to offer much higher sensitivity and spatial resolution for the in-situ analysis of latent fingermark residues. The chemical composition investigations of latent fingermarks coincide with the literature results. However, due to the very large uncertainties involved in the data, no particular trend could be established for the ageing and gender studies using integration or chemometric analyses. The uncertainties were the result of varying quantities of the deposits, although the peak assignments indicate that the fingermark residues were relatively homogenous within the sample and that a general decrease of deposit quantity was occurring over time. The importance of selectively choosing glandular secretions was observed in the differences of their chemical composition to skin cell debris. This study does highlight however, that due to the chemical variation of fingermark deposits between donors, investigating new possibilities for more general reagents may prove more successful than developing a very specific fingermark reagent.

\subsection{Conclusion}

This study has shown that synchrotron sourced IR microscopy is superior to conventional IR for in-situ fingermark studies as its greater spatial resolution enables skin cell s and debris to be avoided, and its greater brightness generates acceptable quality spectra more rapidly. Transflection mode spectra are dominated by $\mathrm{CH}$ stretching vibrations of the lipid portion of fingermark deposit, which does not display significant variation across a fingermark nor as a function of age of the print and the gender and age of the donor. However, as expected, a general decrease in overall spectral intensity, due to evaporation of the lipids, was observed over time.

The observed lack of significant variability in the lipid composition of fingermarks with the age of donors, gender and age of the fingermark is noteworthy, as it indicates that latent 
fingermark visualisation reagents that target lipids (such as Oil Red O) should give accurate and reliable renditions of fingermarks.

\section{Acknowledgements}

Part of this research was undertaken on the infrared microspectroscopy beamline at the Australian Synchrotron, Victoria, Australia. Thanks go to Peter Chapman for his support in all computer and lab related queries and the Australian Synchrotron staff for their expert help and support. Furthermore, Mark Maric is thanked for his expertise and insight into using and applying chemometrics. P. Fritz is supported by an Australian Postgraduate Award. K. Lepkova thanks Curtin University for a Curtin Research Fellowship. K.F. Lim thanks the University of Canterbury for a Visiting Erskine Fellowship. Lastly, all the fingermark donors are thanked for their contribution.

\section{References}

[1] J. Almog, Visualization, in: J.A. Siegel, P.J. Saukko, G.C. Knupfer (Eds.) Encyclopedia of Forensic Sciences, Oxford, 2000, pp. 890-900.

[2] D.K. Williams, R.L. Schwartz, E.G. Bartick, Analysis of latent fingerprint deposits by infrared microspectroscopy, Appl. Spectros., 58 (2004) 313-316.

[3] N.E. Archer, Y. Charles, J.A. Elliot, S. Jickells, Changes in the lipid composition of latent fingerprint residue with time after deposition on a surface, Forensic Sci. Int., 154 (2005) 224-239.

[4] A. Hemmila, J. McGill, D. Ritter, Fourier transform infrared reflectance spectra of latent fingerprints - a biometric gauge for the age of an individual, J. Forensic Sci., 53 (2008) 369-376.

[5] R. Bhargava, R. Schwartz-Perlman, D.C. Fernandez, I.W. Levin, E.G. Bartick, Noninvasive detection of superimposed latent fingerprints and inter-ridge trace evidence by infrared spectroscopic imaging, Anal. Bioanal. Chem., 394 (2009) 2069-2075.

[6] T. Chen, Z.D. Schultz, I.W. Levin, Infrared spectroscopic imaging of latent fingerprints and associated forensic evidence, Analyst, 134 (2009) 1902-1904.

[7] E. Widjaja, Latent fingerprints analysis using tape-lift, Raman microscopy, and multivariate data analysis methods, Analyst, 134 (2009) 769-775.

[8] R. Ramotowski, Advances in fingerprint technology, 2 ed., CRC Press, Boca Raton, 2001.

[9] S.K. Bramble, J.S. Brennan, Chemistry of print residue, in: J. Siegel, P. Saukko, G. Knupfer (Eds.) Encyclopedia of Forensic Sciences, Oxford, 2000, pp. 862-869.

[10] N. Liappis, A. Jaekel, Secretion of free amino acids in human exocrine sweat, Arch. Dermatol. Res., 254 (1975) 185-203.

[11] K.G. Asano, C.K. Bayne, K.M. Horsman, M.V. Buchanan, Chemical composition of fingerprints for gender determination, J. Forensic Sci., 47 (2002) 805-807.

[12] E. Bartick, R. Schwartz, R. Bhargava, M. Schaeberle, D. Fernandez, I. Levin, Spectrochemical Analysis and Hyperspectral Imaging of Latent Fingerprints, in: 16th Meeting of the International Association of Frensic Sciences, Montpellier, France, 2002. 
[13] G.M. Mong, C.E. Petersen, T.R.W. Clauss, Advanced Fingerprint Analysis Project Fingerprint Constituents, Pacific Northwest National Laboratory, US Department of Energy, 1999.

[14] J. Almog, H. Sheratzki, M. Elad-Levin, A.E. Sagiv, G.D. Singh, O.P. Jasuja, Moistened Hands Do Not Necessarily Allude to High Quality Fingerprints: The Relationship Between Palmar Moisture and Fingerprint Donorship, J. Forensic Sci., 56 (2011) 162165.

[15] O.P. Jasuja, M.A. Toofany, G. Singh, G.S. Sodhi, Dynamics of latent fingerprints: The effect of physical factors on quality of ninhydrin developed prints - A preliminary study, Sci. Justice, 49 (2009) 8-11.

[16] L. Ferguson, R. Bradshaw, R. Wolstenholme, M. Clench, S. Francese, Two-Step Matrix Application for the Enhancement and Imaging of Latent Fingermarks, Anal. Chem., 83 (2011) 5585-5591.

[17] C. Weyermann, C. Roux, C. Champod, Initial Results on the Composition of Fingerprints and its Evolution as a Function of Time by GC/MS Analysis, J. Forensic Sci., 56 (2011) 102-108.

[18] R. Wolstenholme, R. Bradshaw, M.R. Clench, S. Francese, Study of latent fingermarks by matrix-assisted laser desorption/ionisation mass spectrometry imaging of endogenous lipids, Rapid Commun. Mass Sp., 23 (2009) 3031-3039.

[19] R.S. Croxton, M.G. Baron, D. Butler, T. Kent, V.G. Sears, Variation in amino acid and lipid composition of latent fingerprints, Forensic Sci. Int., 199 (2010) 93-102.

[20] D.R. Ifa, N.E. Manicke, A.L. Dill, R.G. Cooks, Latent Fingerprint Chemical Imaging by Mass Spectrometry, Science, 321 (2008) 805.

[21] D.K. Williams, C.J. Brown, J. Bruker, Characterization of children's latent fingerprint resiudes by infrared microspectroscopy: Forensic implications, Forensic Sci. Int., 206 (2011) 161-165.

[22] D.L. Perry, T.J. Wilkinson, M.C. Martin, W.R. McKinney, Application of Synchrotron Infrared Microspectroscopy to the Study of Fingerprints, Ernest Orlando Lawrence Berkeley National Laboratory, Berkeley, 2004.

[23] T.J. Wilkinson, D.L. Perry, M.C. Martin, W.R. McKinney, Synchrotron radiation identified human chemical fingerprints - a novel forensic approach, Lawrence Berkeley National Laboratory, Berkeley, 2002.

[24] S.W. Lewis, K.F. Lim, W. van Bronswijk, K. Lepkova, Personal Communication, (2010).

[25] B.C. Smith, Fundamentals of Fourier Transform Infrared Spectroscopy, CRC Press, Boca Raton, 1996.

[26] K. Nakanishi, P.H. Solomon, Infrared absorption spectroscopy, Holden-Day, Inc, Oakland 1977.

[27] H. Horvath, Gustav Mie and the scattering and absorption of light by particles: Historic developments and basics, J. Quant. Spectrosc. Ra., 110 (2009) 787-799.

[28] H. Eberhardt, The Regulation of Sebum Excretion in Man, Arch. Dermatol., 251 (1974) 149.

[29] L.M. McIntosh, M. Jackson, H.H. Mantsch, M.F. Stranc, D. Pilavdzic, A.N. Crowson, Infrared Spectra of Basal Cell Carcinomas are Distinct from Non-Tumor-Bearing Skin Components, J. Invest. Dermatol., 112 (1999) 951-956. 


\section{Table Captions}

Table 1: The inorganic and organic constituents present in glandular secretions that may contribute to fingermark residues [1].

Table 2: Infrared spectrometry instrument parameters.

Table 3: Functional groups found in latent fingermarks by assigning IR microscopy signals [2].

Table 4: Donor information relevant to the synchrotron IR microscopy ageing studies. 


\begin{tabular}{c|c|c}
\hline Gland type & Inorganic substituents & Organic substituents \\
\hline \hline Eccrine & Chlorides & Amino Acids \\
\hline & Sodium & Urea \\
\hline & Potassium & Lactic Acid \\
\hline & Ammonia & Proteins \\
\hline & Sulfates & Sugars \\
\hline Apocrine & Iron & Creatinine \\
\hline & & Proteins \\
\hline Sebaceous & & Carbohydrates \\
\hline & & Cholesterol \\
\hline & & Fatty Acids \\
\hline & & Hydrocarbons \\
\hline
\end{tabular}




\begin{tabular}{c|c|c|c|c|c}
\hline Instrument & Objective & Scans & $\begin{array}{l}\text { Aperture } \\
(\boldsymbol{\mu m})\end{array}$ & $\begin{array}{l}\text { Resolution } \\
\left(\mathbf{c m}^{-\mathbf{1}}\right)\end{array}$ & $\begin{array}{l}\text { Wavenumber } \\
\text { Range }\left(\mathbf{c m}^{-\mathbf{1}}\right)\end{array}$ \\
\hline \hline $\begin{array}{c}\text { Synchrotron-sourced } \\
\text { reflection IR microscopy }\end{array}$ & $36 \times$ & 256 & $10 \times 10$ & 4 & $3800-700$ \\
\hline $\begin{array}{c}\text { Conventional-sourced } \\
\text { reflection IR microscopy }\end{array}$ & $15 \times$ & 256 & 30 & 4 & $4000-400$ \\
\hline $\begin{array}{c}\text { Conventional-sourced } \\
\text { transmission IR spectrometer }\end{array}$ & - & 4 & open & 4 & $4000-650$ \\
\hline
\end{tabular}




\begin{tabular}{c|c|c}
\hline Frequency $\left(\mathbf{c m}^{-1}\right)$ & Vibration & $\begin{array}{c}\text { Lipid/Protein } \\
\text { Assignment }\end{array}$ \\
\hline \hline 3281 & N-H stretch $\left(2^{\circ}\right.$ amide $)$ & Protein \\
\hline 2923 & $\mathrm{C}-\mathrm{H}$ stretch $\left(1^{\circ}\right.$ carbon $)$ & Lipid \\
\hline 2854 & $\mathrm{C}-\mathrm{H}$ stretch $\left(2^{\circ}\right.$ carbon $)$ & Lipid \\
\hline 1741 & $\mathrm{C}=\mathrm{O}$ stretch $($ saturated ester $)$ & Protein \\
\hline 1655 & $\mathrm{C}=\mathrm{O}\left(2^{\circ}\right.$ amide $)$ & Protein \\
\hline 1546 & Major: $\mathrm{N}-\mathrm{H}$ in-plane bend $\left(2^{\circ}\right.$ & Protein \\
\hline 1463 & $\mathrm{Cinor}^{\circ} \mathrm{C}-\mathrm{N}$ stretch & Lipid \\
\hline 1379 & $\mathrm{CH}_{3}$ asymmetric bend & Lipid \\
\hline 1233 & $\mathrm{CH}_{2}$ symmetric bend & Lipid \\
\hline 1160 & $\mathrm{CH}_{3}$ symmetric bend & Protein \\
\hline 1113 & $\mathrm{C}-\mathrm{N}$ stretch $\left(2^{\circ}\right.$ amide $)$ & Lipid \\
\hline & C-C-O stretch (saturated ester $)$ & Lipid \\
\hline
\end{tabular}




\begin{tabular}{c|c|c|c}
\hline Age & Number of donors & Male & Female \\
\hline \hline Under 20 & 3 & 1 & 2 \\
\hline Between 20-30 & 2 & 1 & 1 \\
\hline Between 30-40 & 1 & 0 & 3 \\
\hline Between 40-50 & 6 & 3 & 0 \\
\hline Over 50 & 1 & 1 & 1 \\
\hline
\end{tabular}




\section{Figure Captions}

Fig. 1: Preliminary analysis of latent fingermarks on a $\mathrm{KBr}$ disc using conventional IR microscopy. The absorbances of interest are annotated. Instrument parameters: 4 scans, open aperture, $4 \mathrm{~cm}^{-1}$ resolution.

Fig. 2: Comparison of spectra obtained from fresh (a) and 6 week old (b) latent fingermark samples on a $\mathrm{KBr}$ disc using conventional IR spectroscopy. Instrument parameters: 4 scans, open aperture, 4 $\mathrm{cm}^{-1}$ resolution.

Fig. 3: Sequence of steps taken from depositing a fingermark, to visualising the glandular secretions within each fingermark ridge using a 36x visible objective. Instrument parameters: 36× objective, 256 scans, $10 \mu \mathrm{m}$ aperture, $4 \mathrm{~cm}^{-1}$ resolution.

Fig. 4: Comparison of IR spectra obtained using synchrotron (a) and conventional microscopy (b) of the same fingermark sample on a polished stainless steel plate and measured a few days apart. Instrument parameters: $36 \times$ objective, 256 scans, $10 \mu \mathrm{m}$ aperture, $4 \mathrm{~cm}^{-1}$ resolution, synchrotron sourced IR microscopy; $15 \times$ objective, 256 scans, $10 \mu \mathrm{m}$ aperture, $4 \mathrm{~cm}^{-1}$ resolution, conventional sourced IR microscopy.

Fig. 5: Comparison of synchrotron IR spectra from latent fingermark deposits obtained using a polished stainless steel plate and reflection (a), and a ZnSe substrate and transmission (b). Instrument parameters: $36 \times$ objective, 256 scans, $10 \mu \mathrm{m}$ aperture, $4 \mathrm{~cm}^{-1}$ resolution.

Fig. 6: Comparison of spectra from skin cell debris (a) and glandular secretions (b) found within a latent fingermark sample on a gold-coated glass plate analysed with synchrotron IR microscopy. Instrument parameters: $36 \times$ objective, 256 scans, $10 \mu \mathrm{m}$ aperture, $4 \mathrm{~cm}^{-1}$ resolution.

Fig. 7: Comparison of IR spectra from a fresh fingermark (Feb 2010, a) and an aged fingermark (Aug 2010, b) using synchrotron IR microscopy on the same sample, deposited on polished stainless steel plate. Instrument parameters: $36 \times$ objective, 256 scans, $10 \mu \mathrm{m}$ aperture, $4 \mathrm{~cm}^{-1}$ resolution.

Fig. 8: PCA scores plots of the $\mathrm{CH}$ stretching region as a function of gender of donor (a), age of donor (b) and ageing of the sample (c). 


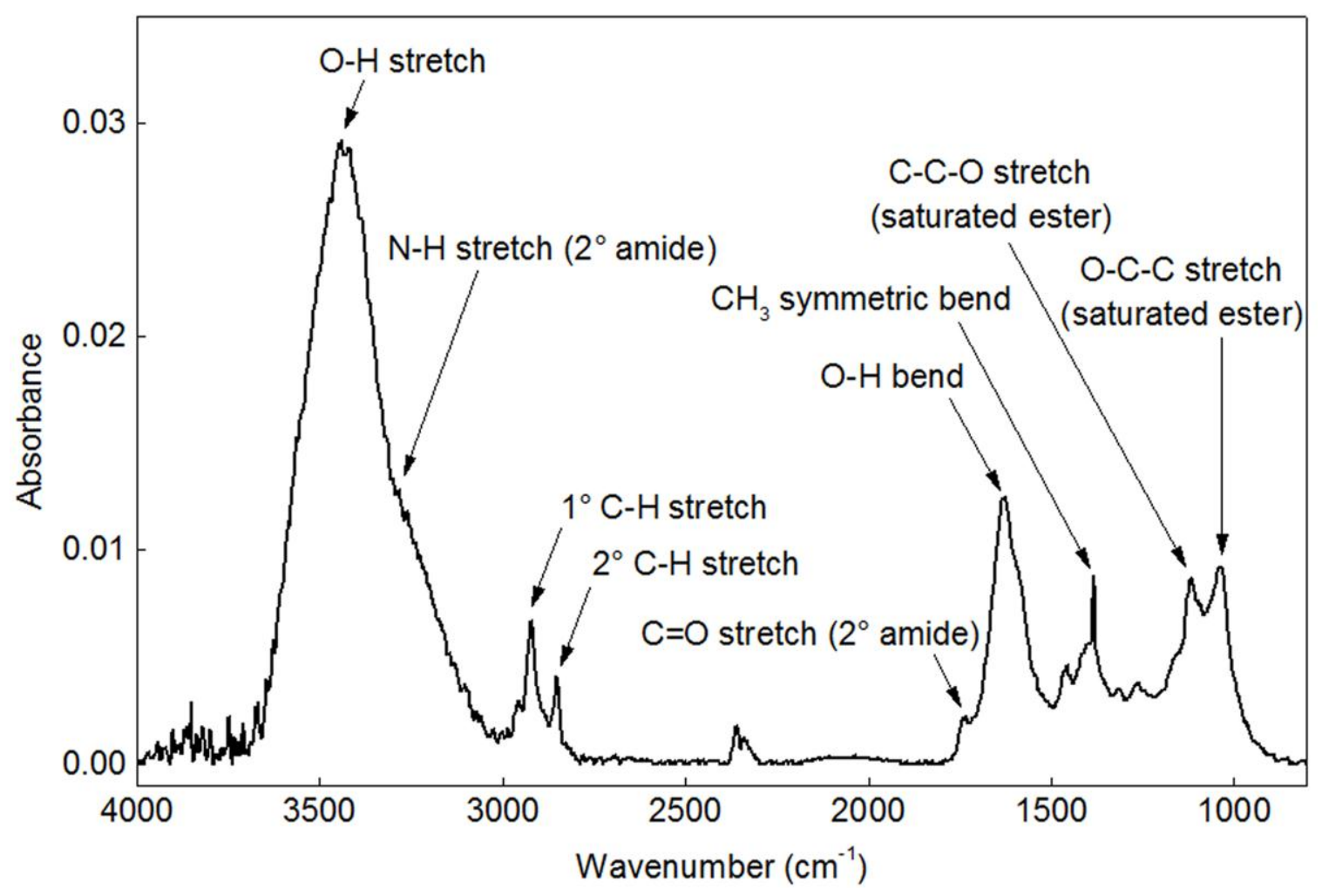

Figure 1

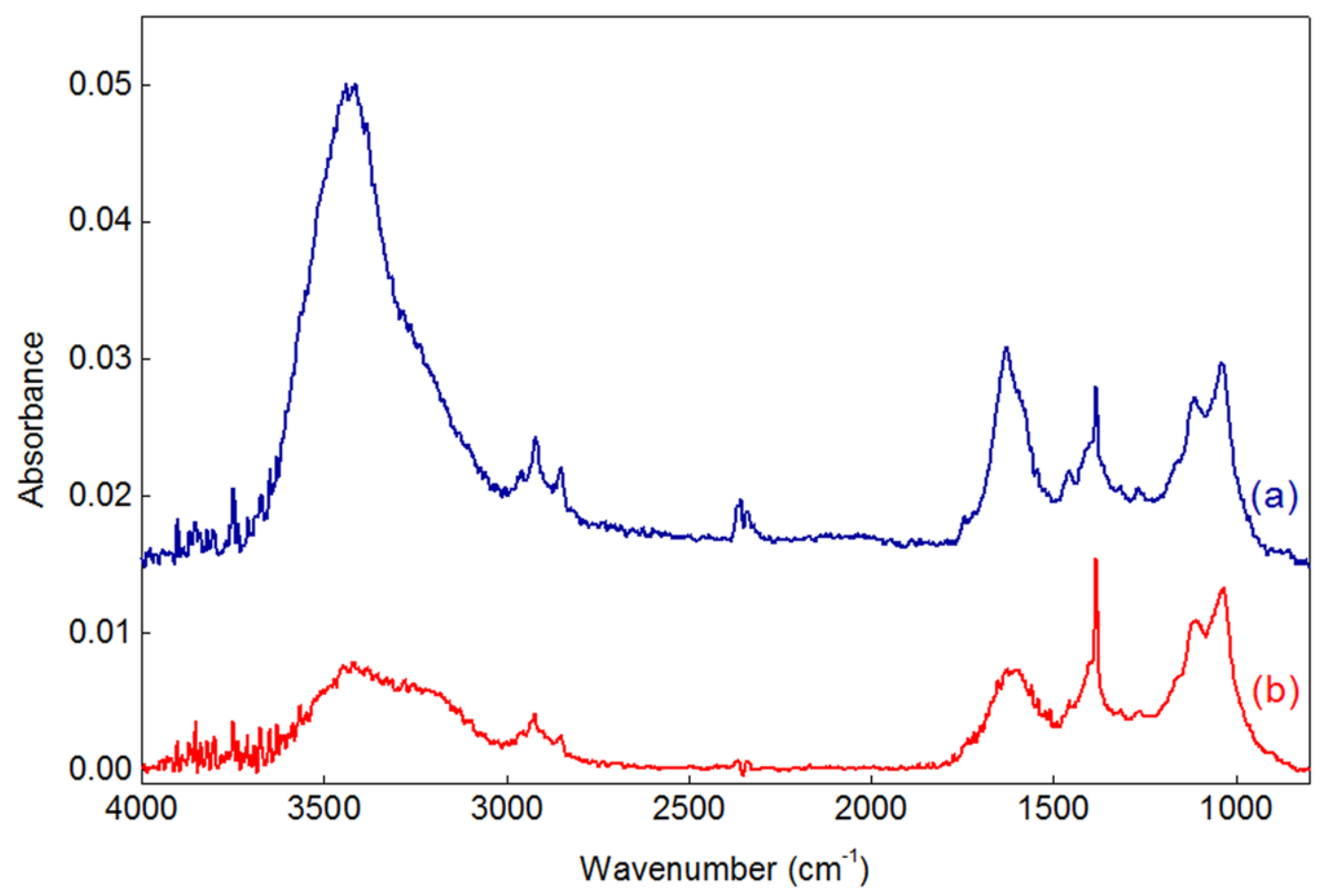

Figure 2 
Fingermark on gold plated glass

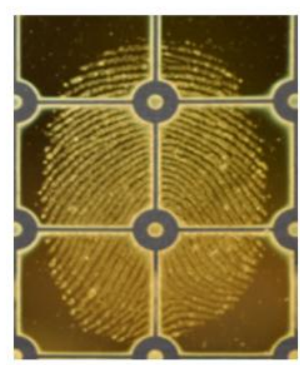

Mosaic of fingermark

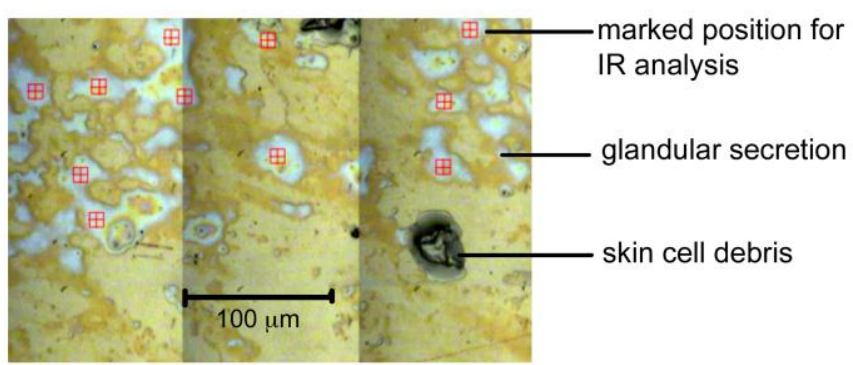

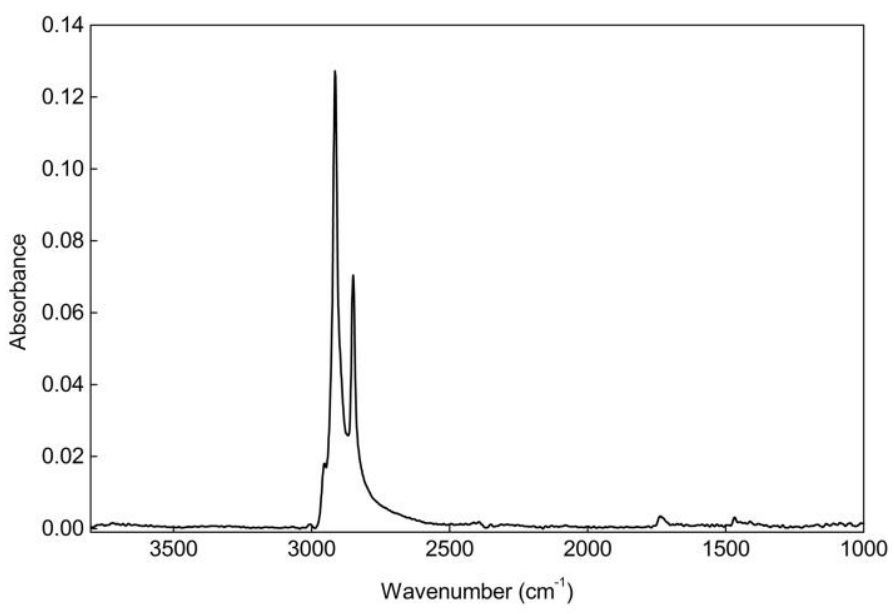

Synchrotron IR microscopy spectrum

Figure 3 


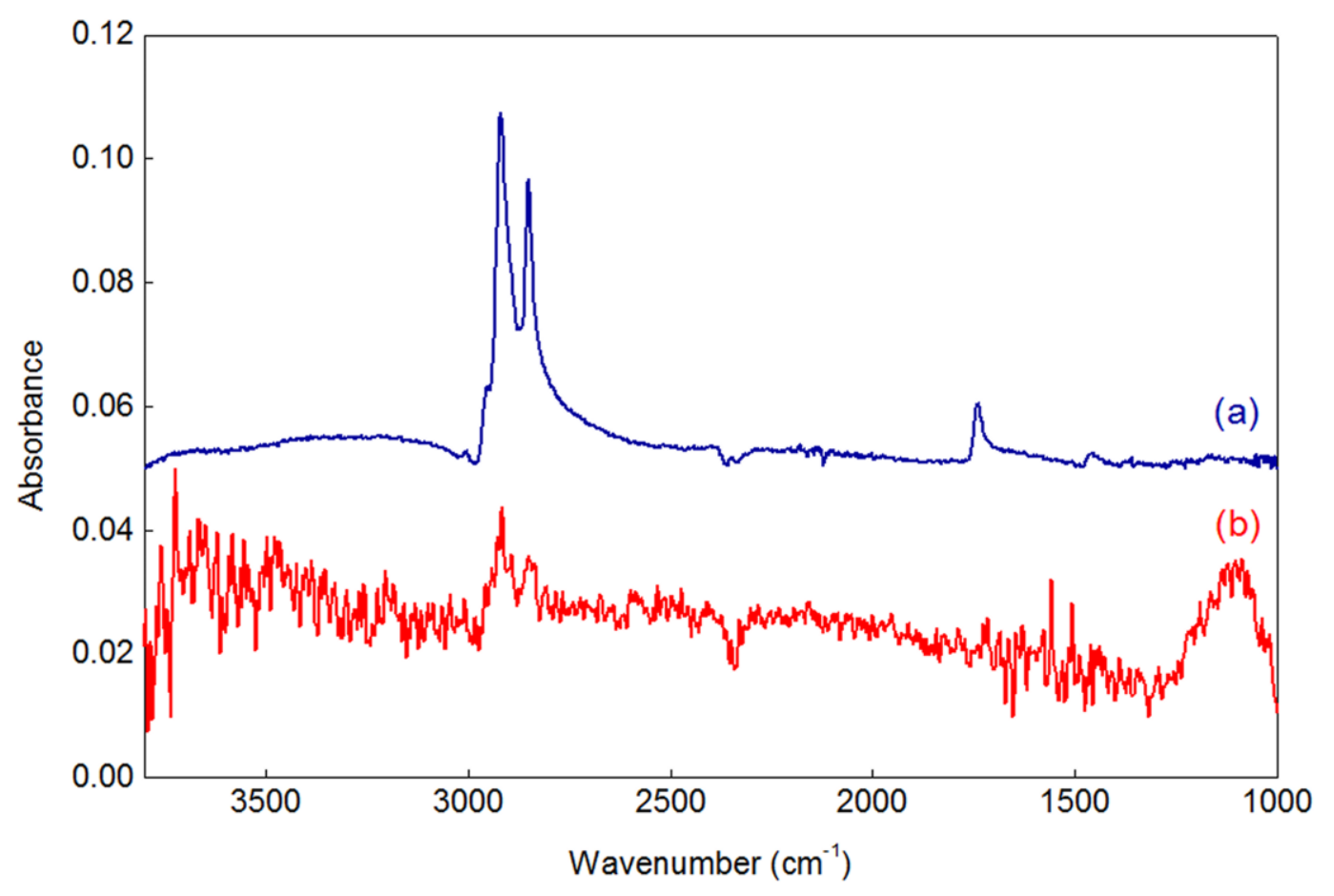

Figure 4

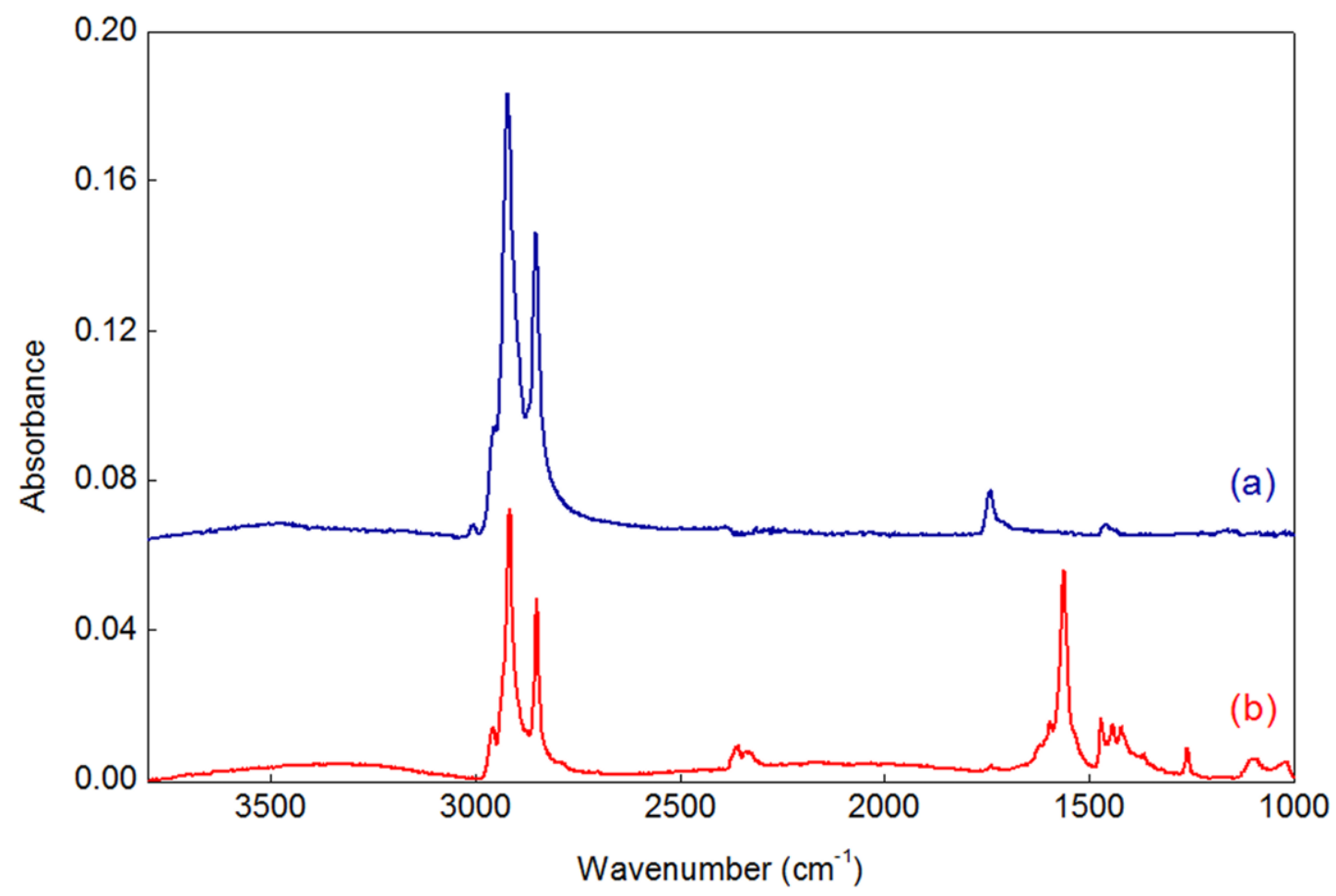

Figure 5 


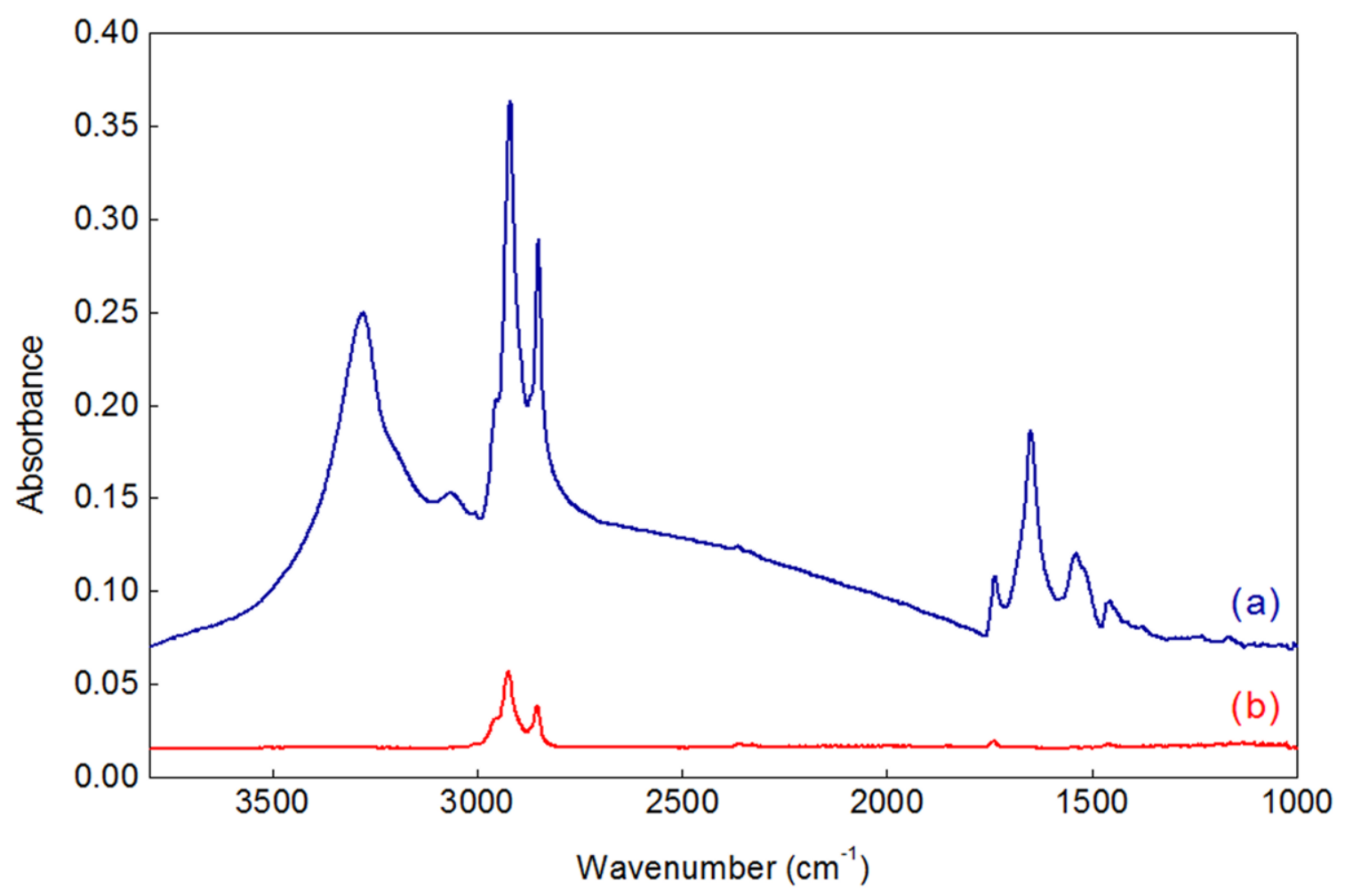

Figure 6

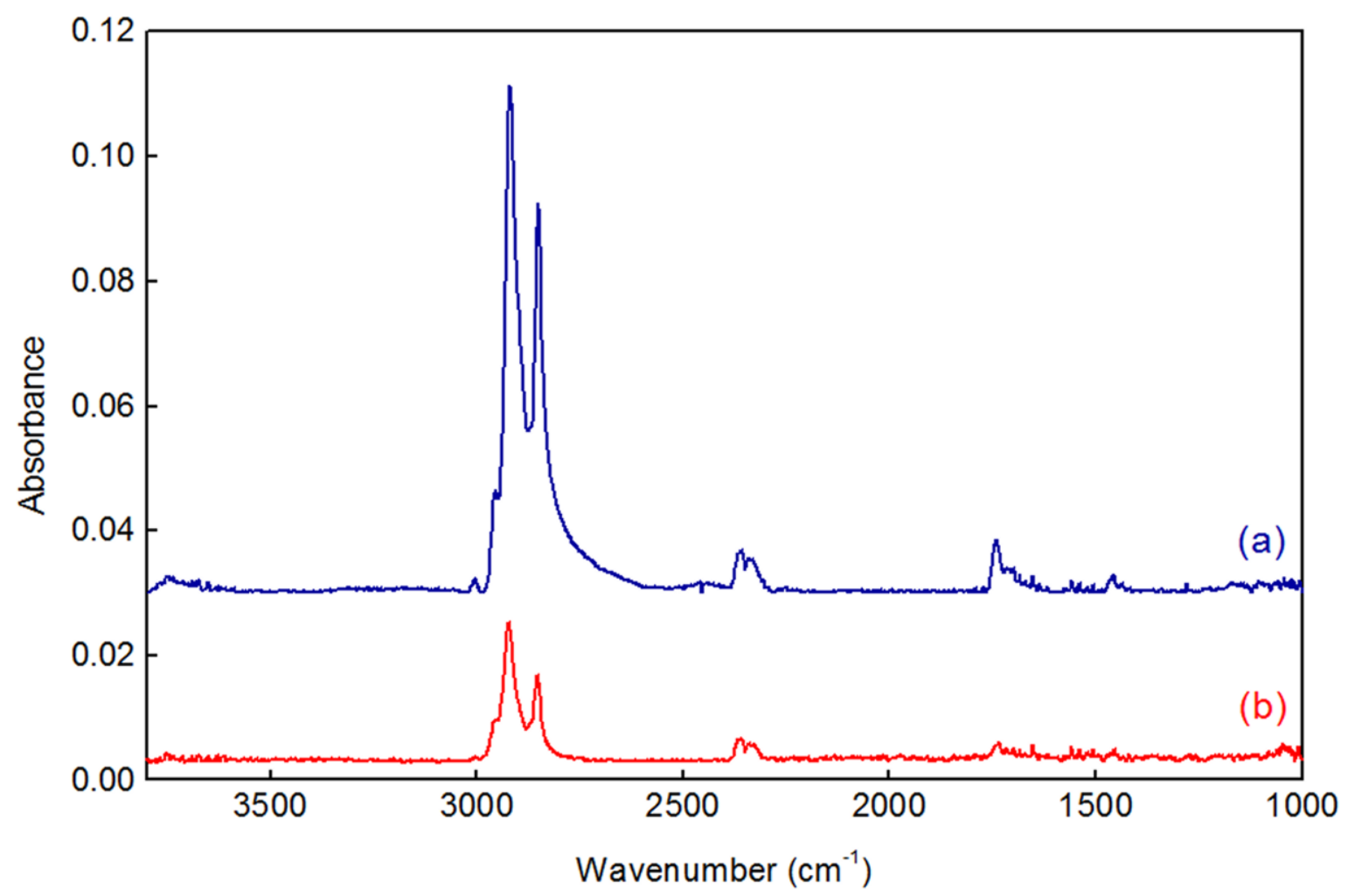

Figure 7 
(a)

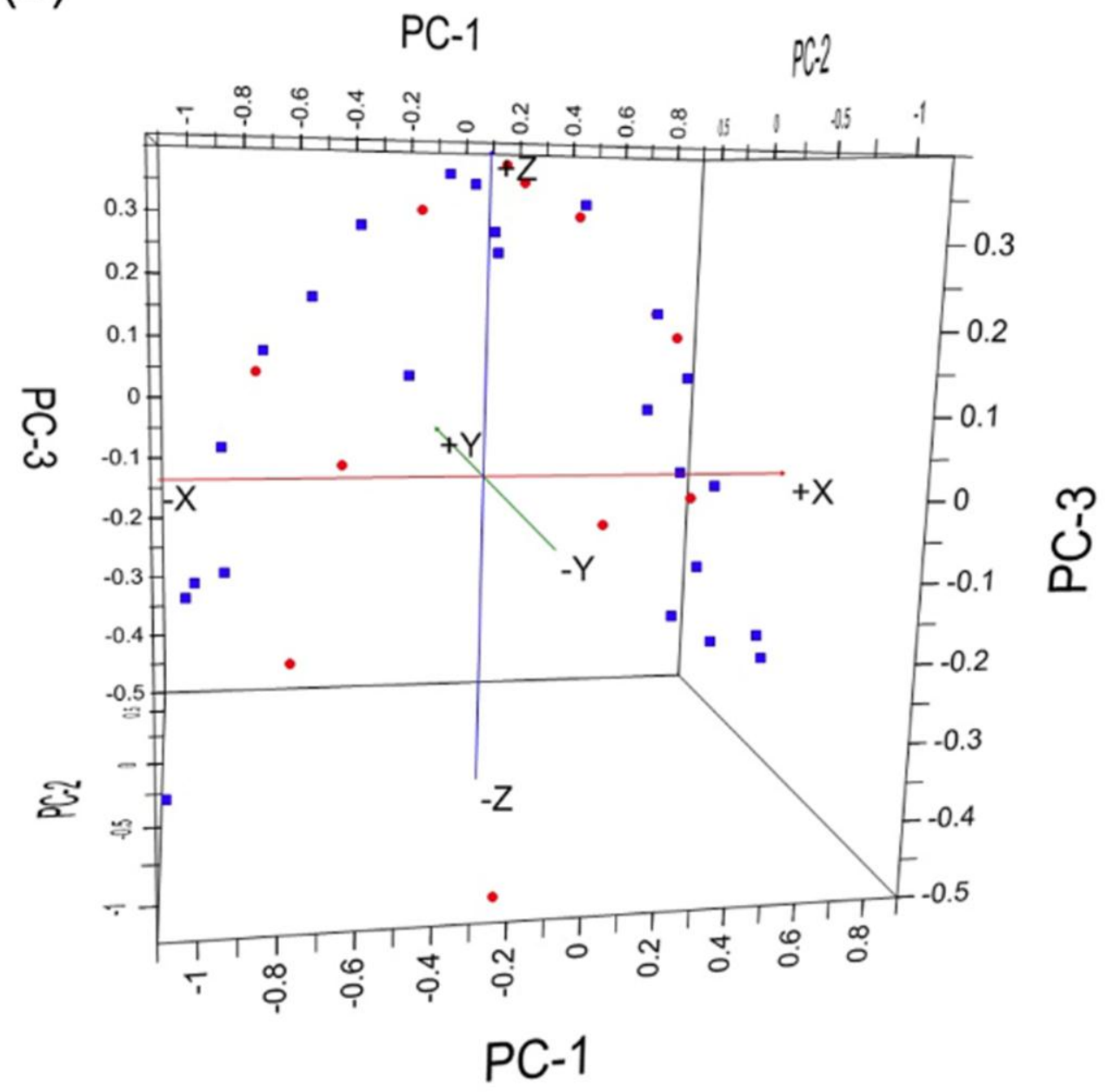

- over 25 - under 25

Figure 8 a 
(b)

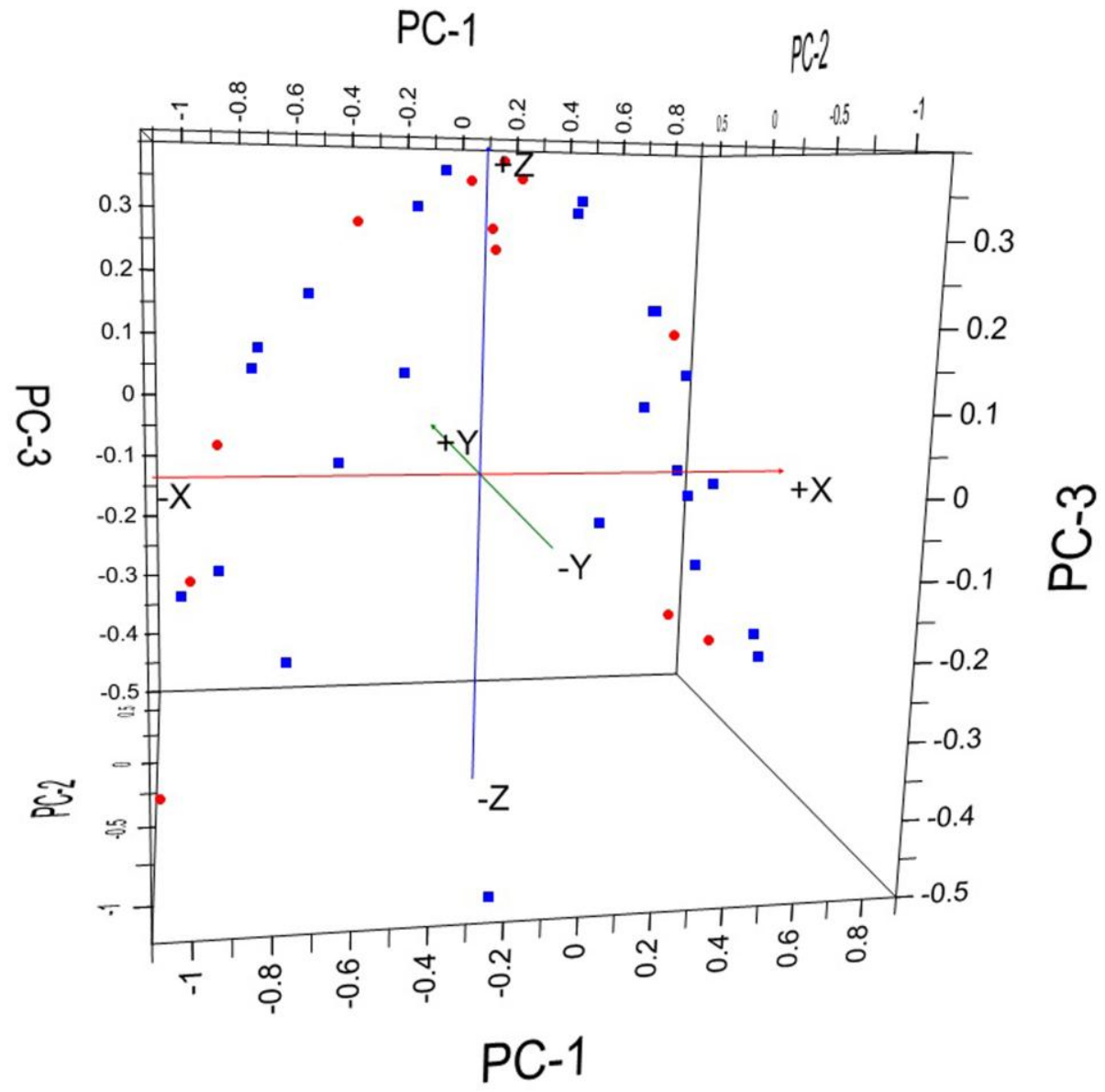

- Female - Male

Figure $8 b$ 
(c)

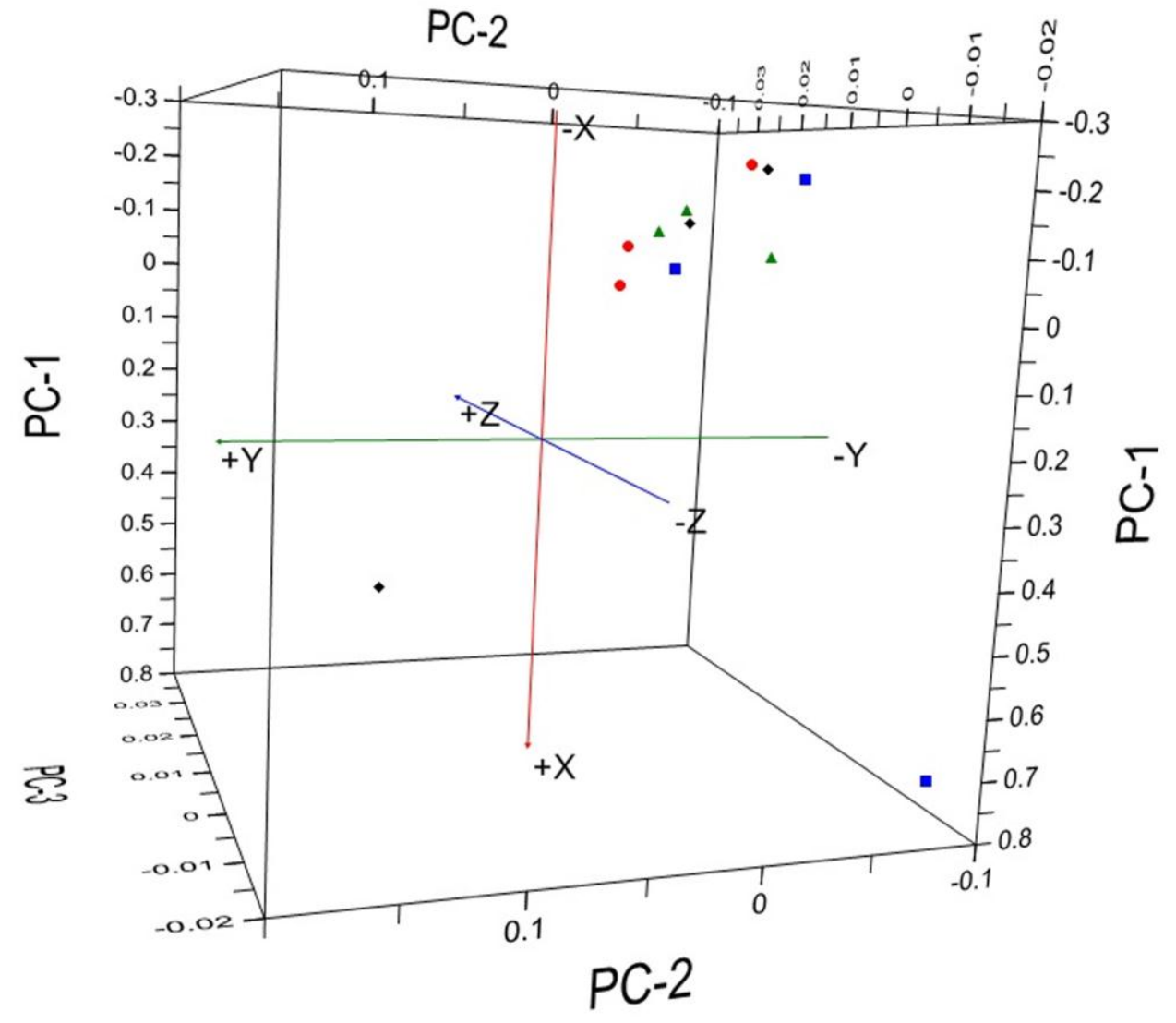

- Initial $\quad 3$ months $\quad 6$ months $\triangle 9$ months

Figure $8 \mathrm{c}$ 


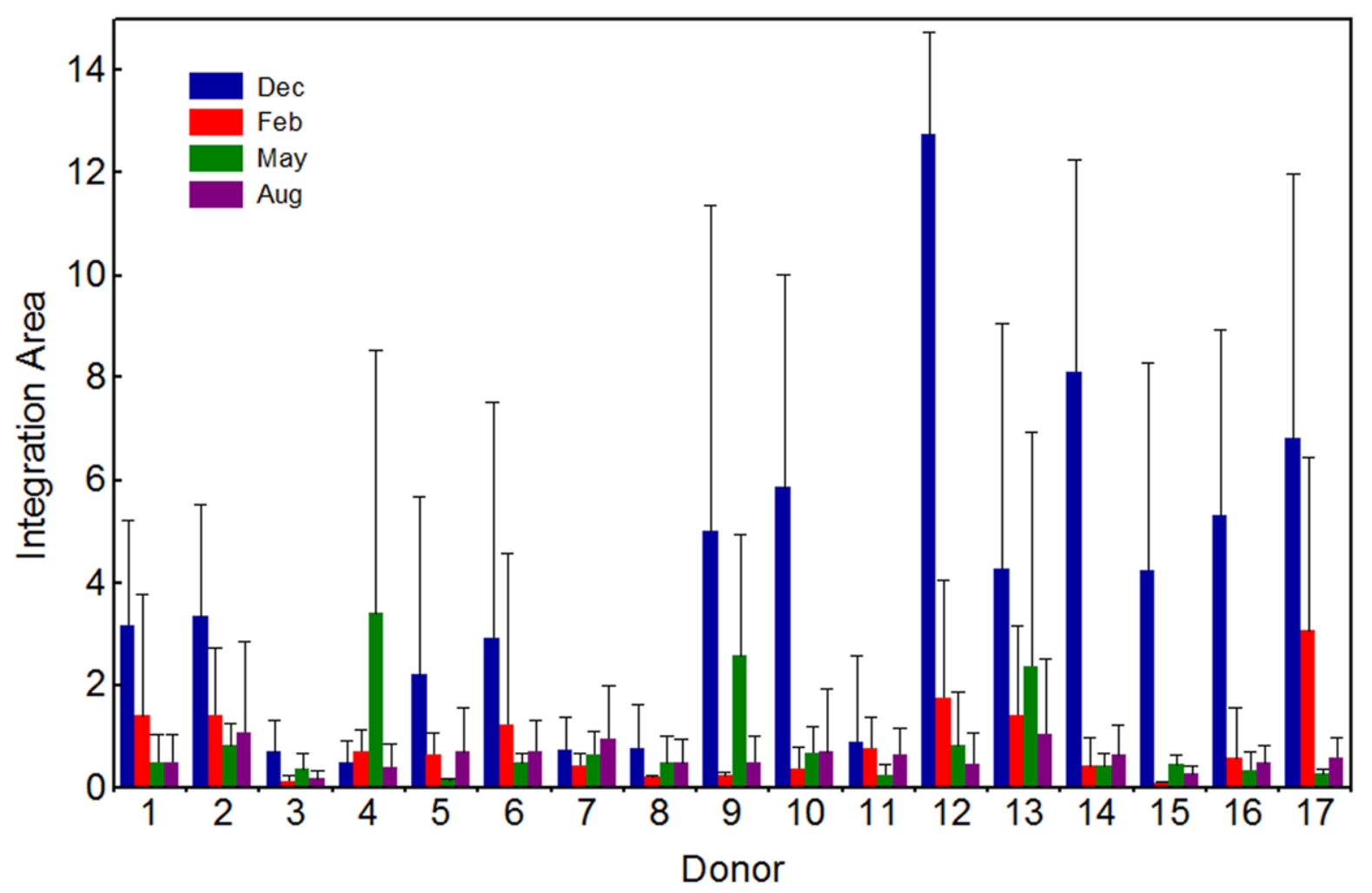

Fig S1 Comparison of the integration area $\left(2970-2833 \mathrm{~cm}^{-1}\right)$ of the lipid C-H stretch attained from fingermark samples of various donors on a gold coated glass plate over a period of 9 months, where each set of columns are from left-to-right Dec 2009, Feb 2010, May 2010 and Aug 2010. Spectra obtained using synchrotron IR microscopy (replicates $=3-20$ ). Instrument parameters: $36 \times$ objective, 256 scans, $10 \mu \mathrm{m}$ aperture, $4 \mathrm{~cm}^{-1}$ resolution. 


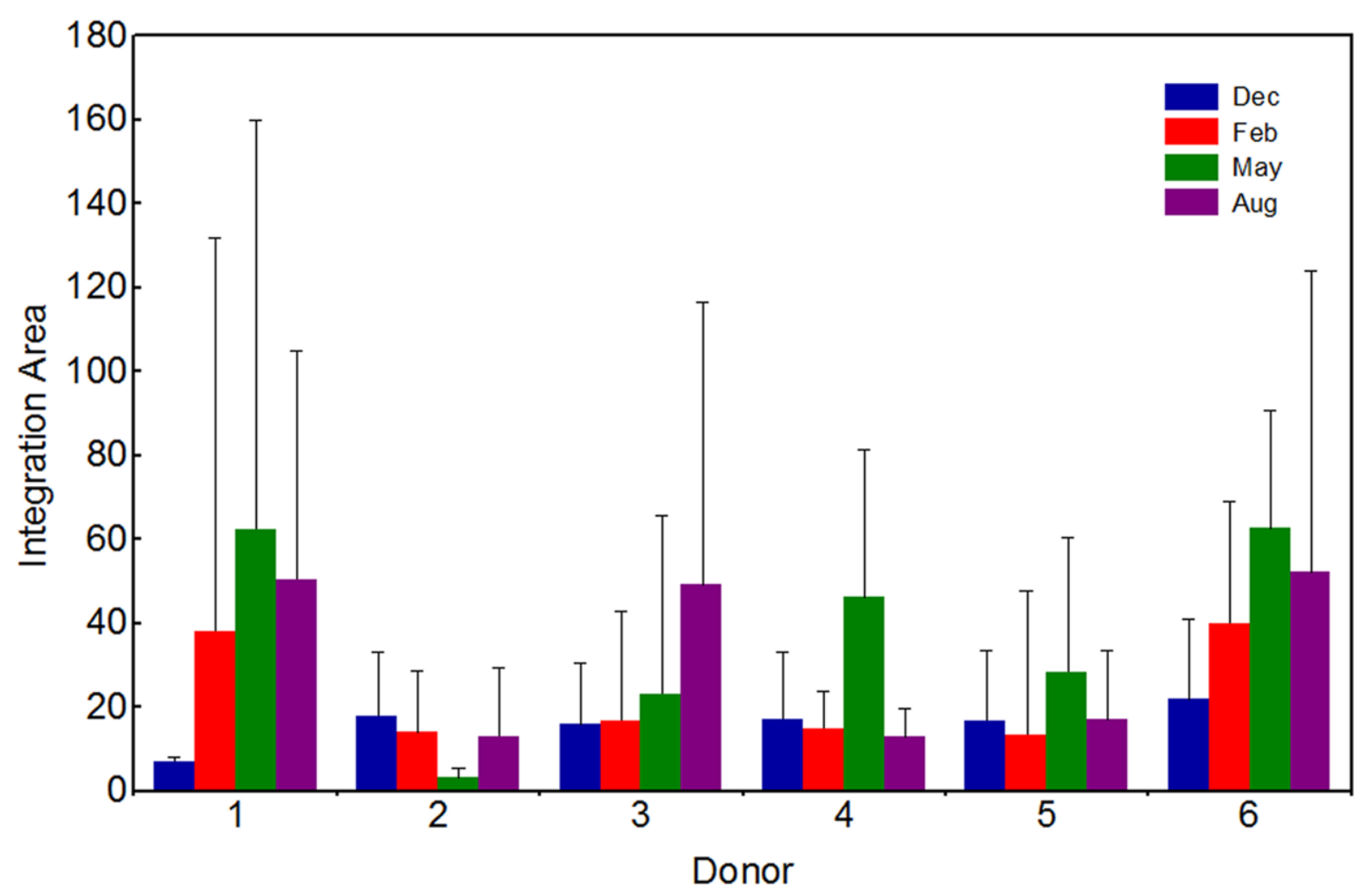

Fig S2 Comparison of the integration ratio of the lipid -C-H $\left(2970-2833 \mathrm{~cm}^{-1}\right)$ to the ester $(1770$ $1720 \mathrm{~cm}^{-1}$ ) stretch attained from fingermark samples of various donors on a gold coated glass plate over a period of 9 months. Spectra obtained using synchrotron IR microscopy (replicates $=4-15$ ). Instrument parameters: $36 \times$ objective, 256 scans, $10 \mu \mathrm{m}$ aperture, $4 \mathrm{~cm}^{-1}$ resolution. 